\title{
Induction of birth in the bandicoot (Isoodon macrourus) with prostaglandin and oxytocin
}

\author{
R. T. Gemmell \\ Department of Anatomical Sciences, The School of Biomedical Science, \\ The University of Queensland, St Lucia, Qld 4072, Australia
}

As in eutherians, maturation of the fetal pituitary and adrenal glands together with an increase in prostaglandin and mesotocin or oxytocin production initiates birth in marsupials. In this study, prostaglandin (Lutalyse) or oxytocin (Syntocinon) were administered to pregnant bandicoots at 05:00 $\mathrm{h}$ on the calculated day of birth and the resultant effects were filmed for analysis. The administration of prostaglandin caused the bandicoot to adopt the birth position several minutes after injection $(n=2)$. However, the bandicoot did not give birth for several hours. Birth occurred at a similar time of day to that observed for untreated bandicoots $(n=7)$, between 08:00 $\mathrm{h}$

\section{Introduction}

During the development of a marsupial, the young have to leave the internal nutritive environment of the uterus and move to the external environment of the pouch to receive nourishment via a teat. The cues and mechanisms used by the mother and the young to perform this transition are not fully understood. The developmental stage of the fetus would appear to determine the duration of gestation and the mother has the fine control of determining when the birth will occur during the $24 \mathrm{~h}$. The development of the fetal pituitary and adrenal glands influences the duration of gestation in monotremes, marsupials and eutherians (Thorburn and Rice, 1987; Nathanielsz, 1996). Several hormones, including oxytocin and prostaglandin, are thought to influence the contractility of uterine muscle. Thus, the development of the fetus and subsequent hormonal changes result in birth in eutherians (Nathanielsz, 1996). Recent evidence indicates that birth in the marsupial is under a similar hormonal control.

Eutherians vary in their stage of development at birth. The lamb has fur, has sight and is nearly independent after birth, whereas rodents are blind, nude and have to be kept in a nest until they reach a stage of independence. Newborn marsupials are immature compared with rodents and are housed in a pouch where most of their development takes place. Newborn marsupials have active pituitary and adrenal glands at birth, and prostaglandin and oxytocin or mesotocin are present in the blood of the mother at birth

Email: r.gemmell@mailbox.uq.edu.au and 12:00 h. After an injection of oxytocin, the bandicoot assumed the birth position and birth occurred within several minutes. The young were alive while still connected to their allantoic stalks. However, they were unable to attach to the teats and did not survive $(n=4)$. The induced young were the colour of venous blood and died soon after the umbilicus was separated, indicating that the cardiopulmonary system of these neonates was underdeveloped and inadequate to maintain life. The results from this study demonstrate that prostaglandin is required to prepare the bandicoot for birth, and mesotocin is required for contraction of the uterus and for birth to occur.

(Gemmell and Rose, 1989; Renfree and Shaw, 1996). As with eutherians, the maturation of the fetal pituitary and adrenal glands in marsupials allows for the secretion of cortisol, which in turn leads to increased prostaglandin and mesotocin production, resulting in increased uterine contractions and birth (Renfree and Shaw, 1996).

Parturition has been studied extensively in the tammar wallaby, Macropus eugenii. Lutectomy on day 23 of the 26 day gestation caused an immediate decrease in progesterone, but it did not initiate birth (Young and Renfree, 1979). However, maintenance of a high plasma progesterone concentration did not delay birth (Ward and Renfree, 1984). The plasma concentration of a metabolite of $\mathrm{PGF}_{2 \alpha}$ increased $1 \mathrm{~h}$ before birth and decreased to basal concentrations within $15 \mathrm{~min}$ after birth (Lewis et al., 1986). Administration of prostaglandin synthetase inhibitors delayed parturition (Renfree et al., 1994). An increase in mesotocin receptors was reported in the pregnant tammar wallaby 3 days before birth (Sebastian et al., 1998) and infusions of an oxytocin receptor antagonist (Atobisan) delayed birth when administered from day 24 of gestation onwards (Renfree et al., 1996). These findings have led Renfree and Shaw (1996) to conclude that the key hormones affecting uterine contractions and birth in the tammar wallaby are prostaglandin and mesotocin. These authors suggested that cortisol from the fetus may increase prostaglandin production by the uterus or placenta, and that prostaglandin either alone or with mesotocin increases uterine contractions and initiates birth.

The bandicoot has a short gestation, 12.5 days, and gives birth to a litter. The plasma progesterone concentration has 
Table 1. Time of birth of young from untreated bandicoots and from bandicoots treated with hormones

\begin{tabular}{cccc}
\hline & \multicolumn{2}{c}{ Day of lactation on which: } & \\
\cline { 2 - 3 } $\begin{array}{l}\text { Bandicoot } \\
\text { no. }\end{array}$ & $\begin{array}{c}\text { mating } \\
\text { occurred }\end{array}$ & $\begin{array}{c}\text { subsequent young } \\
\text { were born }\end{array}$ & $\begin{array}{c}\text { Time of day young } \\
\text { born (h) }\end{array}$ \\
\hline Normal births of bandicoots & & & \\
1 & 46 & 58 & $12: 05$ \\
2 & 45 & 57 & $11: 30$ \\
3 & 45 & 57 & $11: 26$ \\
4 & 45 & 57 & $09: 09$ \\
5 & 47 & 59 & $08: 40$ \\
6 & 46 & 58 & $12: 00$ \\
7 & 44 & 56 & $10: 19$ \\
Induction with prostaglandin analogue & & $09: 25$ \\
8 & 45 & 57 & \\
9 & 46 & 58 & $06: 11$ \\
Induction with oxytocin & & & $05: 45$ \\
10 & 47 & 59 & $05: 36$ \\
11 & 49 & 61 & $08: 07$ \\
12 & 44 & 56 & \\
13 & 44 & 56 & \\
\hline
\end{tabular}

been shown to increase to $12.6 \mathrm{ng} \mathrm{ml}^{-1} 4$ days before birth and is maintained at this value for at least 7 days. The concentration of $\mathrm{PGF}_{2 \alpha}$ increases from basal concentrations at day 1 before birth to $2534 \mathrm{pg} \mathrm{ml}^{-1}$ at birth and remains high for 2 days after birth (Gemmell et al., 1980). The day of mating can be calculated by collecting a sample from the vaginal sac of the female bandicoot and determining the presence of spermatozoa. The duration of gestation does not vary, and birth always takes place between 08:00 $\mathrm{h}$ and 12:00 $\mathrm{h}$ on day 12 after mating ( $n=14$; Gemmell et al., 1982; $n=4$; Gemmell et al., 1999). This constancy in the date and time of birth allows the initiation of birth to be examined. In this study, prostaglandin (Lutalyse) or oxytocin (Syntocinon) were administered to pregnant bandicoots on the calculated day of birth and the resultant effects were filmed for analysis.

\section{Materials and Methods}

\section{Animals and treatments}

The bandicoots used in this study were from a breeding colony of Isoodon macrourus housed in large (30 m × $30 \mathrm{~m})$ outside enclosures at the Native Animal Research Unit, Pinjarra Hills. Details of capture and maintenance of bandicoots were described by Gemmell (1982). Female bandicoots with pouch young at approximately day 7 were housed with an adult male bandicoot in a $3 \mathrm{~m} \times 6 \mathrm{~m}$ outside enclosure. The bandicoots were maintained on dog food (Drimeat dog ration; Provincial traders Pty Ltd, Queensland) and supplied with water ad libitum. The animals were examined at least once a week. Each bandicoot was lightly anaesthetized with a halogen:oxygen mixture to facilitate examination and weighing.

During the breeding season, bandicoots wean their young at approximately day 58 of lactation, 1 day before the birth of the subsequent litter on day 59 (Gemmell and Johnston, 1985). Thus, with a gestation period of 12.5 days, ovulation and mating must occur at about day 46 of lactation. Vaginal caecal samples were obtained from bandicoots each day at 08:00 $\mathrm{h}$ from day 44 to day 50 of lactation. Material from the lumen of the vaginal caecae was obtained using the method described by Lyne (1976). A polyethythylene tube with an outside diameter of $1.0 \mathrm{~mm}$ was passed through the urogenital sinus and along a lateral vagina into a vaginal caecum. The catheter tube, $10 \mathrm{~cm}$ in length, was stiffened with a thin flexible wire that was removed after insertion. A syringe with a $23 \mathrm{G}$ needle was used to flush $0.1 \mathrm{ml}$ of saline into the caecum and some of the contents were then drawn into the catheter tube. This sample was placed on a microscope slide and the presence of motile spermatozoa was noted. Birth occurred in the morning on day 12 after spermatozoa were first detected in the morning sample from the vaginal caecum.

\section{Administration of prostaglandin and oxytocin}

The prostaglandin analogue Lutalyse (5 mg dinoprost tromethamine $\mathrm{ml}^{-1}$; Upjohn Ltd, NSW) was administered i.m. at a dose of $1 \mathrm{ml}$ to two pregnant bandicoots on the calculated day of birth at 05:30 h.

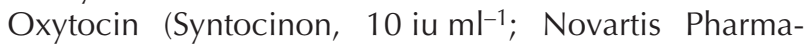
ceuticals Australia Pty Ltd, NSW) was administered i.m. at a dose of $1.0 \mathrm{ml}(n=2)$ and $0.5 \mathrm{ml}(n=2)$ to four pregnant 


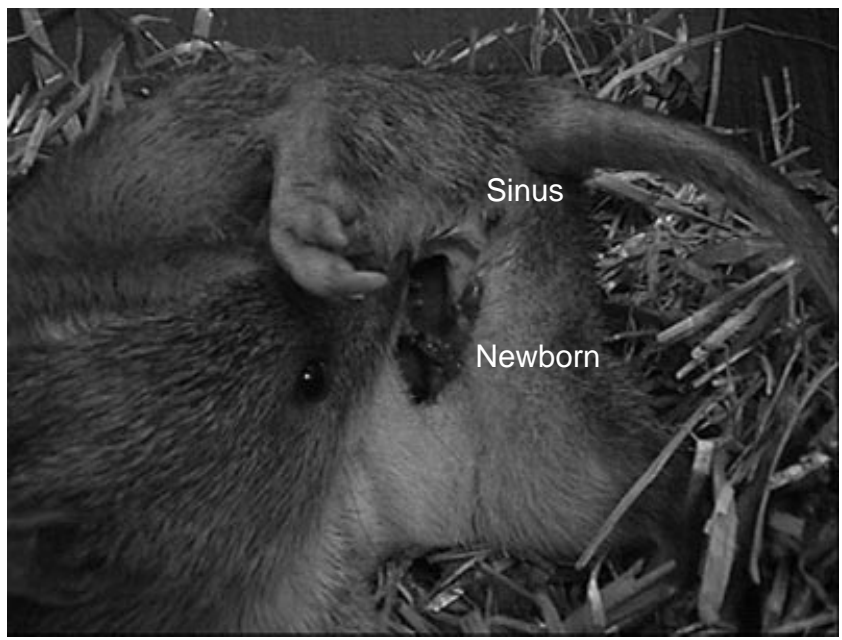

Fig. 1. A bandicoot in the process of giving birth. The mother has positioned her urogenital sinus above the pouch to allow the newborn to enter the pouch.

bandicoots on the calculated day of birth at 05:30 $\mathrm{h}(n=3)$ and 08:00 $\mathrm{h}(n=1)$. The subsequent behaviour of the bandicoots after the injections was recorded at normal speed using a hand-held digital video camera (Sony DCRTRV9E) that allowed continuous recording with a digital time record. Notes made during the experiment supplemented these recordings.

\section{Results}

\section{Normal birth}

Although the mother licks the urogenital sinus and cleans the pouch infrequently up to $6 \mathrm{~h}$ before birth, the frequency of this activity increases $60 \mathrm{~min}$ before birth. Just before birth the mother adopts the birth position by lying on one side and lifting her upper leg. She licks the sinus and the pouch more frequently. As the young appear enveloped in their membranes, the mother vigorously licks the young and removes any fluids from the sinus and surrounding areas. The first young to be born reach the pouch within $1 \mathrm{~min}$ and all the young are in the pouch 4-5 min after birth and are attached to the teats 5-10 min after birth. Birth was filmed for four bandicoots (numbers 1-4) and the time of birth was noted for another three bandicoots (Table 1). These observations of normal birth were described by Gemmell et al. (1999).

\section{Prostaglandin}

Bandicoot no. 8 received a $1 \mathrm{ml}$ i.m. injection of the prostaglandin (Lutalyse) at 05:30 h. The pregnant bandicoot was first observed in the birth position at 05:35 h, licking around the urogenital sinus and in the pouch. This activity continued at approximately $5 \mathrm{~min}$ intervals until birth occurred $5 \mathrm{~h}$ after the injection. Just before birth, the licking by the bandicoot became more animated and the first

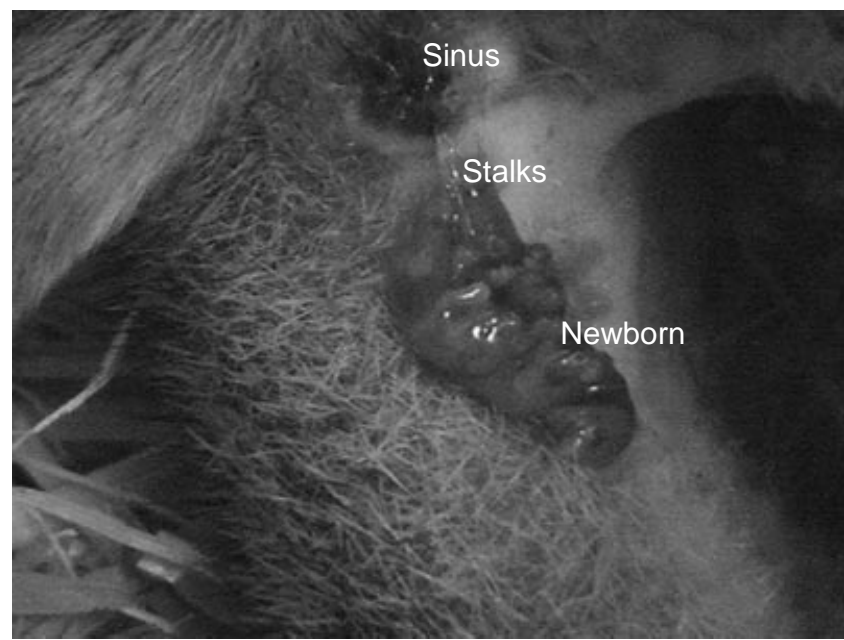

Fig. 2. Several young bandicoots still enclosed in their fetal membranes shortly after being expelled from the urogenital sinus. The newborn are suspended by their allantoic stalks.

young to be born was observed at 10:19 h. Three young were born followed by one more about $30 \mathrm{~s}$ later. All four young reached the pouch 5 min after the start of birth with their allantoic stalks still intact. All four young were observed the following day and they had attached to the small teats that had not been used by the previous litter. Bandicoot no. 9 also received a $1 \mathrm{ml}$ i.m. injection of Lutalyse at 05:30 h. Licking was observed at 05:35 h and birth occurred at 09:25 h. All three young attached to teats.

\section{Oxytocin}

Two female bandicoots received a $1.0 \mathrm{ml} \mathrm{i.m}$. injection of oxytocin (Syntocinon), whereas a further two bandicoots received $0.5 \mathrm{ml}$ oxytocin. All four bandicoots assumed the birth position several minutes after the injection and started to lick the urogenital sinus.

Three young were born at $06: 11 \mathrm{~h}$ to the first bandicoot (no. 10) injected with $1 \mathrm{ml}$ Syntocinon. The mother was very nervous and the young were not very active, as they did not crawl towards the pouch even though they were alive and moving. At 06:12 h, two of these young were hanging by their stalks in the pouch but were unable to attach to a teat. The third young to be born had presumably been detached. A fourth young was born at 06:20 h, 9 min after the birth of the other three young. The two young born earlier that were still attached by their allantoic stalks were alive and moving but did not attempt to enter the pouch or attach to a teat. At 06:33 h, these same two young were still attached by their allantoic stalks but were not near the pouch. At 06:43 h, all four young were detached from the mother with three young on the floor of the enclosure and one young in the nest. The mother was anaesthetized and the four young placed in the pouch. The mother was reexamined at 08:05 $\mathrm{h}$ and all four young in the pouch were dead. None of the four young had attached to a teat. 
In the case of the second bandicoot (no. 11) injected with $1 \mathrm{ml}$ Syntocinon at 05:30 h, the mother was agitated and birth occurred at 05:45 h. The first young enveloped in membranes did not show any movement or signs of life. The second bandicoot was born at 05:46 h. Both young were stuck together and did not move. The third bandicoot was born at 05:50 h. Although this young bandicoot did move, the forearms moved sluggishly compared with normal bandicoots at birth. At 05:55 h, four young were present and two young showed weak movements. By 05:56 h, all four young were stuck together hanging by their twisted allantoic stalks. The young did not attempt to move towards pouch, but the mother continued to clean the sinus and around the pouch. The four young were all present at 06:00 h. Only one young was observed at 06:01 h. One minute later the mother ate the young. At 06:07 h, the mother found the other three young on the floor of the enclosure and ate them.

The third bandicoot (no. 12) was injected with $0.5 \mathrm{ml}$ Syntocinon at 05:30 h. Three young were born at 05:36 h and the uterine fluid was released. The young were all moving, but not as vigorously as observed with young from a normal birth. The young were attached by their allantoic stalks and the mother positioned herself so that the young fell through the entrance to the pouch although the young did not try to attach to a teat. The young were still moving at 05:58 $\mathrm{h}$ attached by their stalks. The mother ate the young at 06:03 h.

The fourth bandicoot (no. 13) was injected with $0.5 \mathrm{ml}$ Syntocinon at 08:00 h. After the release of fluid, the first bandicoot was born at 08:07 $\mathrm{h}$ and the mother positioned the young over the pouch. A second bandicoot was observed hanging down from the sinus at 08:09 h. The second young dropped into the entrance of the pouch. At 08:14 h the birth of two more young was observed after the release of yellow fluid. At 08:15 h, the mother was observed eating something. At 08:19 h, one young was observed on the ground (no. 3) and one young hanging (no. 4) from the sinus. Another two bandicoots were born at 08:22 $\mathrm{h}$. Three bandicoots were observed hanging from the sinus attached by their allantoic stalks and were moving slowly as the mother licked in and around the pouch. At 08:25 h one of these young fell to the ground and the allantoic stalk broke. The young bandicoot was moving when it reached the ground and then there was no movement. This young bandicoot was retrieved from the ground and filmed. However, no movement was observed at 08:30 h. The mother was anaesthetized at 08:55 $\mathrm{h}$ and one dead young, not attached to a teat, was found within the pouch. None of the other four young were found. The remaining two young were fixed in buffered formalin and the body weights of these young were 228 and $201 \mathrm{mg}$.

All four Syntocinon-treated females delivered live young. One of the major differences with young from a normal birth was the body colour. The Syntocinon-induced young were the colour of venous blood, a dark red, whereas the young of a normal birth were bright red as seen in oxygenated blood. However, the major difference was in the reduced mobility of the young and their inability to attach to the teat. As soon as the allantoic stalks of the Syntocinon-induced young were broken, the young ceased moving.

\section{Discussion}

Administration of prostaglandin induced the female bandicoot to adopt the birth position several minutes after the injection. However, the bandicoot did not give birth for several hours. Birth occurred at a similar time of day to that observed for untreated bandicoots. However, after the administration of oxytocin the bandicoot assumed the birth position and birth occurred several minutes later. Administration of $1 \mathrm{ml}$ Syntocinon to two bandicoots induced birth immediately, but the young did not survive. A reduction of the volume of Syntocinon to $0.5 \mathrm{ml}$ also resulted in the death of the young.

In premature humans and sheep, the underdevelopment of the cardio-pulmonary system may result in death. The bandicoot has a short gestation period, 12.5 days, and implantation is thought to occur at about day 9 of gestation (Lyne and Hollis, 1977). Therefore, to increase the chance of survival of the induced litter, $0.5 \mathrm{ml}$ Syntocinon was administered at 08:00 h. Unfortunately, the young still did not survive. It may be that the induction of birth in the bandicoot is not feasible because of the requirement of the 3.5 days of organogenesis between day 9.0 and day 12.5 of gestation. The body weights of the dead induced young were 228 and $201 \mathrm{mg}$, whereas the body weight of normal bandicoot young has been reported to be about $240 \mathrm{mg}$ (Hughes, 1962; Lyne, 1964, 1974; Gemmell et al., 1988). The colour of the induced young and their subsequent death when the placental blood supply was removed indicate that an underdeveloped cardio-pulmonary system was the cause of death. It may be possible to induce the birth of a litter and ensure survival if the induction is carried out close to the expected time of birth. However, birth normally occurs between 08:00 $\mathrm{h}$ and 14:00 $\mathrm{h}(n=14$; Gemmell et al., 1982); 10:00 $\mathrm{h}$ and 12:00 $\mathrm{h}(n=4$; Gemmell et al., 1999) and in the present study between $08.40 \mathrm{~h}$ and 12:00 $\mathrm{h}$ ( $n=7$; Table 1$)$. The possible death of other litters to obtain this result negates continuing the treatment. The results obtained indicate that prostaglandin is required to prepare the female bandicoot for birth and oxytocin is required for expulsion of the young.

Rose and MacFadyen (1997) reported the role of prostaglandin and oxytocin in the reproductive behaviour of the bettong, Betongia gaimardi. Administration of prostaglandin or oxytocin induced birth behaviour in adult nonpregnant and immature female and male bettongs, although oxytocin had a longer latency period between injection and birth behaviour compared with prostaglandin. When a prostaglandin inhibitor (Finadyne) was administered before the oxytocin injection, birth behaviour did not occur. Rose and MacFadyen (1997) concluded that oxytocin exerts its 
behavioural effects via prostaglandin synthesis. The results from the present study are in agreement with this proposal. Oxytocin did initiate birth behaviour and subsequent birth.

Prostaglandin is involved in the birth process. Injections of prostaglandin induce parturient behaviour in several marsupial species including the bandicoot (Hinds et al., 1990; Shaw, 1990; Gemmell et al., 1991). Female tammar wallabies treated with indomethacin, a prostaglandin inhibitor, did not show birth behaviour or give birth. Six pregnant tammar wallabies with a normal gestation period of 26-27 days were treated with indomethacin from day 24 to day 28 of gestation. At autopsy on day 28, two tammar wallabies had aborted, seven had dead fetuses and three had live fetuses. Nine of these ten young were markedly post mature (Renfree et al., 1994). These authors concluded that prostaglandin was essential for normal birth. The results of the present study demonstrate that administration of prostaglandin initiates birth behaviour but does not appear to initiate the expulsion of the young. The results of a study by Rose and MacFadyen (1997) indicate that administration of oxytocin probably causes the release of prostaglandin and as a result the bandicoot prepares for birth. The injected oxytocin stimulates the contraction of the uterine muscle and birth occurs.

Birth was delayed in tammar wallabies receiving continuous infusion of the oxytocin receptor antagonist Atosiban for 3-7 days from day 24. Control tammar wallabies gave birth at day 26.75 and Atosiban-treated tammar wallabies gave birth at day 27.85 (Renfree et al., 1996). The authors concluded that mesotocin was important for parturition in marsupials. Two explanations were given for the delay in birth. First, prostaglandin stimulated uterine muscle contraction even when the mesotocin-induced uterine contractility was reduced with Atosiban and the delay was a result of the additional time necessary to build up prostaglandin concentrations in the presence of Atobisan. Alternatively, the delay in birth was required to reach the threshold concentration of mesotocin in the presence of Atobisan. The results of the present study indicate that Syntocinon increases uterine muscle contractility and initiates birth in the bandicoot, thus supporting the second explanation.

The effect of administration of oxytocin to marsupials has been examined on two occasions. Tyndale-Biscoe (1963) injected Pituitrin (synthetic oxytocin) into ovariectomized quokkas, Setonix brachyurus, each day from day 16 to day 18. Two dead young were observed at autopsy on day 26 . A preliminary study of one tammar wallaby indicated that injections of mesotocin or prostaglandin near term caused uterine contractions and expulsion of the fetus (Shaw, 1983; Renfree and Shaw, 1996). After injections of oxytocin and Cloprostenol, a prostaglandin analogue, to a pregnant tammar wallaby on day 23 that induced strong uterine contractions, fetal membranes were found beneath the cage on day 24. In the present study, oxytocin administered to pregnant bandicoots did cause premature birth of live young, which were capable of movement for at least $30 \mathrm{~min}$ after birth. The skin colour of the young indicated that the circulatory system of the newborn had not matured. Presumably the lack of oxygen inhibited their ability to attach to the teats.

\section{References}

Gemmell RT (1982) Breeding bandicoots in Brisbane (Marsupialia: Peramelidae) Australian Mammalogy 5 187-194

Gemmell RT and Johnston G (1985) The development of thermoregulation and the emergence from the pouch of the marsupial bandicoot (Isoodon macrourus). Physiological Zoology 58 299-302

Gemmell RT and Rose RW (1989) The senses involved in movement of some newborn Macropodidae and other marsupials from cloaca to pouch. In Kangaroos, Wallabies and Rat Kangaroos pp 339-347 Eds I Hume and G Grigg, Australian Mammal Society and Surrey Beatty and Sons, Sydney, Australia

Gemmell RT, Jenkin G and Thorburn GD (1980) Plasma concentrations of progesterone and 13,14-dihydro-15-keto-prostaglandin $\mathrm{F}_{2 \alpha}$ at parturition in the bandicoot (Isoodon macrourus). Journal of Reproduction and Fertility $60253-256$

Gemmell RT, Singh-Asa P, Jenkin G and Thorburn GD (1982) Ultrastructural evidence for steroid hormone product in the adrenal gland of the marsupial, Isoodon macrourus, at birth Anatomical Record 203 505-512

Gemmell RT, Johnston G and Bryden MM (1988) Osteogenesis in two marsupial species, the bandicoot Isoodon macrourus, and the possum Trichosurus vulpecula. Journal of Anatomy 159 155-164

Gemmell RT, McFadyen AS and Rose RW (1991) Induction of parturient behaviour in possums (Marsupilia: Phalangeridae) and bandicoots (Marsupialia: Peramelidae) Australian Mammalogy 14 133-135

Gemmell RT, Veitch C and Nelson J (1999) Birth in the northern bandicoot Isoodon macrourus (Marsupilia: Peramelidae) Australian Journal of Zoology 47 517-528

Hinds LA, Tyndale-Biscoe CH, Shaw G, Fletcher TP and Renfree MB (1990) Effects of prostaglandin and prolactin on luteolysis and parturient behaviour in the non-pregnant tammar (Macropus eugenii). Journal of Reproduction and Fertility 88 323-333

Hughes RL (1962) Role of the corpus luteum in marsupial reproduction Nature (London) 194 890-891

Lewis PR, Fletcher TP and Renfree MB (1986) Prostaglandin in the peripheral plasma of tammar wallabies during parturition Journal of Endocrinology 111 103-109

Lyne AG (1964) Observations on the breeding and growth of the marsupial Perameles nasuta Geoffroy, with notes on other bandicoots Australian Journal of Zoology 12 322-339

Lyne AG (1974) Gestation period and birth in the marsupial (Isoodon macrourus). Australian Journal of Zoology 22 303-309

Lyne AG (1976) Observations on oestrus and the oestrous cycle in the marsupials Isoodon macrourus and Perameles nasuta. Australian Journal of Zoology 24 513-521

Lyne AG and Hollis DE (1977) The early development of marsupials, with special reference to bandicoots. In Reproduction and Evolution pp 293-302 Eds JH Calaby and CH Tyndale-Biscoe. Australian Academy of Science, Canberra, Australia

Nathanielsz PW (1996) The timing of birth American Scientist 84 562-569

Renfree MB and Shaw G (1996) Reproduction of a marsupial: from uterus to pouch Animal Reproduction Science 42 393-403

Renfree MB, Shaw G and Fletcher TP (1994) Evidence for the essential role of prostaglandins for parturition in a marsupial (Macropus eugenii). Journal of Reproduction and Fertility 102 433-446

Renfree MB, Parry LJ and Shaw G (1996) Infusion with an oxytocin receptor antagonist delays parturition in a marsupial Journal of Reproduction and Fertility 108 131-137

Rose RW and MacFadyen AS (1997) The role of prostaglandin $F_{2 \alpha}$ and oxytocin in the reproductive behaviour of a marsupial (Bettongia gaimardi). Hormones and Behaviour 31 120-125

Sebastian LT, De Matteo L, Shaw G and Renfree MB (1998) Mesotocin receptors during pregnancy, parturition and lactation in the tammar wallaby Animal Reproduction Science 51 57-74 
Shaw G (1983) Effect of PGF P $_{2 \alpha}$ on uterine activity, and concentrations of 13,14-dihydro-15-keto- $\mathrm{PGF}_{2 \alpha}$ in peripheral plasma during parturition in the tammar wallaby (Macropus eugenii). Journal of Reproduction and Fertility 69 429-436

Shaw G (1990) Control of parturient behaviour by prostaglandin $F_{2 \alpha}$ in the tammar wallaby, (Macropus eugenii). Journal of Reproduction and Fertility 88 335-342

Thorburn GD and Rice GE (1987) Fetal maturation and the timing of parturition: a comparative analysis Proceedings of the Australian Physiological and Pharmacological Society 18 51-68

Tyndale-Biscoe CH (1963) Effects of ovariectomy in the marsupial (Setonix brachyurus). Journal of Reproduction and Fertility 6 25-40

Ward KL and Renfree MB (1984) Effects of progesterone on parturition in the tammar Macropus eugenii. Journal of Reproduction and Fertility $\mathbf{7 2}$ 21-28

Young IR and Renfree MB (1979) The effects of corpus luteum removal during gestation on parturition in the tammar wallaby (Macropus eugenii). Journal of Reproduction and Fertility 56 249-254

Received 14 March 2001.

First decision 14 May 2001.

Final version received 5 October 2001.

Accepted 29 October 2001. 